\title{
A special issue of High Temperature Materials and Processes Dedicated to Professor Dr. Yoshio Waseda on the occasion of his $65^{\text {th }}$ birthday
}

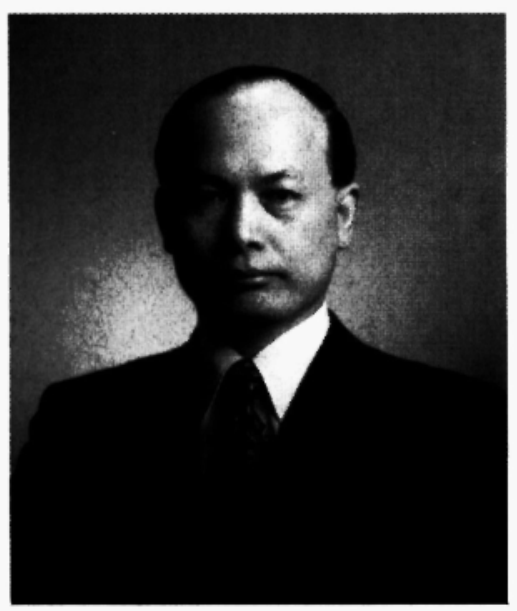

\section{PREFACE}

This issue of the Journal of High Temperature Materials and Processes is dedicated to Professor Dr. Yoshio Waseda on the occasion of his $65^{\text {th }}$ birthday. He is well known to many materials scientists, some physicists and chemists the world over. Throughout his career, first during his active years of research at the University of Toronto, Canada, University of Pennsylvania, USA, Institute Mineral Dressing and Metallurgy, and subsequently Institute for Advanced Materials Processing, Tohoku University, Professor Waseda made several outstanding contributions that influenced the evolution of the discipline. Later he provided administrative leadership as Director of Institutes and afterwards as Vice-President, Tohoku University. He also maintained close relations with professional societies for Metallurgy and Materials Science in Japan.

Professor Waseda is well-known as Editor-in-Chief of the Journal of High Temperature Materials and Processes during the period from 1997 (vol.16) to 2009,( vol.28). He is now Editorial Adviser to the journal. Because of his tireless efforts this journal has gained in international recognition and coverage.

Dr. Waseda, now Professor Emeritus of Tohoku University, was born in October 1945. He graduated from Nagoya Institute of Technology with Shimizu Metal Honors, earned his M.S. in 1970 and Ph.D. in 1973, in Materials Science from Tohoku University. Then, he started his academic career at the laboratories of ferrous and non-ferrous metallurgy of the Institute of Mineral Dressing and Metallurgy, Tohoku University in 1973. He built up the research team on the structure and properties of non-crystalline materials, such as liquid and glassy metals and oxides. Dr. Waseda became a full Professor of Tohoku University in 1986 . He held the position of Visiting Professor and taught graduate courses at the University of Toronto and the University of Pennsylvania.

Professor Waseda is an international authority on the structure of non-crystalline systems. $\mathrm{He}$ is the author/co-author of more than 500 papers and 12 books on structural analysis of metals, alloys and oxides in both liquid and glassy states, theoretical studies of thermodynamic and electronic properties of non-crystalline metallic materials, and thermal conductivity and diffusivity measurements on molten 
and glassy oxides at high temperatures. His book published in 1980 on "The Structure of Non-Crystalline Materials - Liquids and Amorphous Solids" is highly regarded as a standard reference. His research covers a wide range of topics, two major areas are highlighted below:

\section{STRUCTURE AND PROPERTIES OF METALLIC AND OXIDE MELTS INCLUDING AMORPHOUS METALS.}

Until early 1970 s reliable structural data of liquid metals and oxide melts were limited. Professor Waseda's leadership in developing a specially designed high-temperature facility for X-ray diffraction resulted in systematic in situ measurement of the atomic scale structure of metallic and oxide melts and amorphous metals. For example, he has determined quantitatively the distribution of local ordering units and oxygen coordination of metallic ions in non-crystalline silicates, phosphates, borates and ferrites. The results are available in a public database http://1 es.tagen.tohopku.ac.jp/ waseda/scm/AXS/index. html or database of SCM-AXS that can be easily searched through Google.

\section{DEVELOPMENT OF THE ANOMALOUS X-RAY SCATTERING (AXS) FOR MATERIALS CHARACTERIZATION:}

Our understanding of the physics and chemistry of new materials heavily relies on their structure. However, in multi-component disordered materials, a realistic three-dimensional model of the structure is relatively difficult to construct from radial distribution functions. Obtaining information on the local chemical environment around a specific element circumvents this problem. Professor Waseda has used anomalous x-ray scattering (AXS) to obtain partial and environmental structural functions as a function of radial distance. The method has been extended to structural characterization of crystalline and non-crystalline thin films of sub-micron thickness. In his method, it is unnecessary to subtract the contribution of the substrate from the measured intensity. The elegant method using synchrotron radiation, first demonstrated on an oxide glass film of $0.3 \mu \mathrm{m}$ thickness deposited on a silicon wafer, has been subsequently applied to thin films of the high $\mathrm{T}_{\mathrm{c}}$ oxide superconductor, $\mathrm{YBa}_{2} \mathrm{Cu}_{3} \mathrm{O}_{7 \cdot \mathrm{x}}$, superionic conductor, $\mathrm{Cu}_{2} \mathrm{Se}$, and superlattice, $\mathrm{Co}_{9} \mathrm{Fe} / \mathrm{Cu}$, revealing a wealth of new information. The AXS method can be used without subjecting the sample to high vacuum and is suitable for materials that contain neighboring elements of the periodic table.

As seen from this brief report, Professor Waseda has steadily confronted unresolved problems related to the structure and physical chemistry of non-crystalline systems and found elegant solutions which have initiated new trends in research. His unconventional and original approach has resulted in unique breakthroughs. $\mathrm{He}$ has provided leadership to a generation of researchers on the structure of non-crystalline systems and their relationships to macroscopic properties. His pioneering contributions have been recognized through many awards; for example, the Best Paper Award of the Japan Institute of Metals (JIM) in the years 1983, 1986, 1989, 1997,1999, 2001, 2003 and 2006; the Best Paper Award of the Mining and Metallurgical Processing Institute of Japan (MMIJ) in 1998, 2000, 2001, 2003 and 2006; the Leadership award of the TMS (The Minerals, Metals and Materials Society, U.S.A.) in 2000, and the prestigious Medal with Purple Ribbon of the Government of Japan awarded by the Japanese Emperor in 2005 for his distinguished contributions to Materials Science. In May 2010, he was awarded the Honda Memorial Prize, named after Professor Kotaro Honda who is recognized as a pioneer and leader of Physical Metallurgy and Metal Physics in Japan.

Professor Dr. Yoshio Waseda is one of the Japan's most distinguished scientists and professional leaders in the field of Metallurgy and Materials Science. He has directed a new stream of systematic research on futuristic technologies for the $21^{\text {st }}$ century. He has emphasized the need for the creation of a new generation of concepts and processes to produce ultra pure materials, and fine particles with precisely controlled size, shape, habits, structure, and composition. For example, the Japanese government in 1992 accepted 
the proposal of Professor Waseda to create a new institute entrusted with the challenging task of developing and processing exotic materials with designed atomic and molecular configurations. As the founding director of the Institute for Advanced Materials Processing (IAMP), he formulated the strategic policy addressed to the development of a large number of novel engineered materials catering to the needs of electronics and communications industry.

In 1996, Professor Waseda also founded the Research Center for Metallurgical Process Engineering as a crucial arm of this Institute. This center is devoted to the emerging field of Regeneration Process Engineering; exploring new science and developing novel flow paths for materials compatible with improved quality of life. Metallurgical wastes are treated as resources for the development of new materials. This is particularly pertinent because of the global depletion of natural resources and deterioration of global environment, which are serious current and future concerns.

In April, 2002, the Japanese government again accepted his new proposal to create a new institute for conducting systematic and futuristic research on a new generation of concepts, methodologies and processes related highly evolved materials, both organic and inorganic substances and their hybrids. Emphasis was on the design, control and analysis for materials with intricate atomic and molecular architecture for sophisticated functional applications fully harmonized with nature. This new organization was formed by the merger and reorganization of three Institutes of Tohoku University, each of which made distinguished contributions to the evolution of their respective research fields over fifty years. The new Institute is expected to foster multidisciplinary research on advanced materials and processes through synergetic interactions between staff members form different disciplines. Professor Waseda served a founded director of this Institute of Multidisciplinary Research for Advanced Materials (IMRAM).
Professor Waseda has assembled formidable young talent from across Japan and has secured the assistance of leading international authorities through institutionalized visiting professorships to achieve the challenging objectives of the Institute. An important aspect of his style of management is the emphasis on human resources as the crucial ingredient for creative research. Professor Waseda, with his holistic vision for the future of scientific and technological progress harmonized with nature and social development, has made outstanding contributions to the international exchange program for scientists and engineers. Since 1986, the exchange programs supported by the Japanese government such as Japan International Cooperation Agency (JICA) or Japan Society for the Promotion of Science (JSPS) have flourished under his leadership. During this period, about 150 young researchers and engineers from 22 countries were offered an opportunity for upgrading their technical background and enlarging their cultural horizons, and over 70 people received degrees including Ph.D. Many of the young people trained in the design and operation of sophisticated processes have now become key persons in the development of their respective countries.

Recognizing his leadership qualities, Professor Waseda was appointed executive member of several public societies and governmental organizations for science and culture. He has served as President of the Mining and Materials Processing Institute of Japan in 2003, President of the Japan Institute of Metals in 2005, and member of Science Council of Japan since 2006. Professor Waseda served as Vice-president of Tohoku University from 2003 to 2007 .

It is our great pleasure to dedicate this Festschrift to Professor Yoshio Waseda on the occasion of his 65 th birthday. The contributions in this special issue are written by researchers who have academic fields close to Professor Waseda's interests. We hope to have many opportunities for fruitful collaboration with Professor Waseda. We wish Professor Yoshio Waseda the very best in his professional and personal life ahead.

Shigeru Suzuki and Takashi Nakamura 